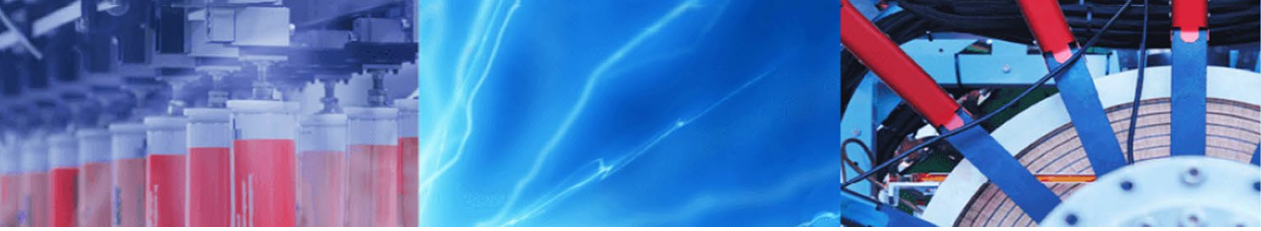

Research Article

\title{
Structural effects on the enhancement of first-cycle Coulombic efficiency of mangrove-derived hard carbon as an anode material in sodium ion batteries
}

\author{
Koji Nakabayashi ${ }^{1,2}$ (D) Chung Dabin ${ }^{1} \cdot$ Yujin $\mathrm{Han}^{1} \cdot$ Jemyung $\mathrm{Oh}^{3} \cdot$ Jin Miyawaki ${ }^{1,2} \cdot$ Seong-Ho Yoon ${ }^{1,2}$
}

(c) Springer Nature Switzerland AG 2019

\begin{abstract}
The effects of material structure on the electrochemical performance of mangrove-derived hard carbon anodes in sodium ion batteries were closely examined. The size and distribution of micropores were controlled by adjusting the preheating step that chars green wood. The electrochemical properties of mangrove-derived hard carbon were significantly improved by optimizing the preheating conditions. Optimal performance, in terms of discharge capacity and first-cycle Coulombic efficiency, was observed following 7 days of preheating at $500^{\circ} \mathrm{C}$. We also examined the influence of ultramicropore structure on the electrochemical properties of mangrove-derived anodes in SIBs.
\end{abstract}

Keywords Mangrove wood $\cdot$ Sodium ion battery Pre-heat treatment

\section{Introduction}

Sodium ion batteries (SIBs) are a promising alternative to lithium ion batteries (LIBs) due to the similar chemical properties of sodium and lithium and the natural abundance and relatively low cost of sodium [1]. Whereas typical anode materials used in LIBs, such as graphite, are not suitable for use in SIBs, hard carbon anodes have shown a reversible capacity of approximately $300 \mathrm{mAh} \mathrm{g}^{-1}$ [2]. In addition, hard carbon can be derived from renewable biomass sources such as sugar [3, 4], cotton wool [5], pinecone hulls [6], peanut shells [7], and rice husks [8].

In recent years, mangrove-derived char has attracted attention as an effective raw material for hard carbon production due to its relatively high abundance and low cost. The total world area of mangrove forests in the year 2000 was $137,760 \mathrm{~km}^{2}$, including 118 countries and territories in the tropics and subtropics [9]. The largest expanses of mangroves are in Asia (42\%), particularly Indonesia (23\%), followed by Africa (20\%), North and Central America (15\%), Oceania (12\%), and South America (11\%) [9].

In a previous study, we found that hard carbon derived from mangrove char and carbonized under vacuum exhibited higher discharge capacities and reversibility than chars carbonized in an argon atmosphere [10]. To increase the yield and initial Coulombic efficiency of SIBs, we developed an additional preheating step in the preparation of mangrove char. This step allowed a greater degree of control over the final electrochemical properties of the resulting hard carbon [11]. Preheating green mangrove wood increased the fixed carbon yield and enabled control of pore size and the distribution and amounts of oxygencontaining functional groups in the final product.

Although sub-nanometer voids or defects in hard carbon have been considered as promising storage sites for sodium ions in SIBs, the relationships between the structure of the hard carbon and the electrochemical performance, such as discharge capacity, first-cycle Coulombic efficiency, cycle ability, and rate performance, remain

Koji Nakabayashi, nakabayashi@cm.kyushu-u.ac.jp | ${ }^{1}$ Department of Applied Science for Electronics and Materials, Kyushu University, Kasuga, Fukuoka 816-8580, Japan. ${ }^{2}$ Institute for Materials Chemistry and Engineering, Kyushu University, Kasuga, Fukuoka 816-8580, Japan. ${ }^{3}$ Department of Materials Science \& Engineering, Adama Science \& Technoloy Unieversity, PO Box 1888, Adama, Ethiopia.

SN Applied Sciences (2019) 1:177| https://doi.org/10.1007/s42452-018-0141-5

Received: 5 September 2018 / Accepted: 20 December 2018 / Published online: 22 January 2019 
unclear. In this study, we incorporated mangrove-derived hard carbon as an anode material in SIBs, using the preheating step developed in our previous work. We closely examined the experimental conditions during char preparation and showed how these parameters can be adjusted to control the final structure of hard carbon as a means of improving the electrochemical performance of SIB systems. The conditions during preheating were particularly important in determining the electrochemical properties of the obtained hard carbon.

\section{Experimental}

\subsection{Sample preparation}

To fabricate mangrove char, green Indonesian mangrove wood (Rhizophora apiculata) was heat-treated for 1-10 days in a bomb reactor with an inner gas pressure of $0.7 \mathrm{MPa}$. The reactor consisted of a stainless steel tube held at temperatures from 450 to $550^{\circ} \mathrm{C}$ (heating rate: $5^{\circ} \mathrm{C}$ $\left.\mathrm{min}^{-1}\right)$. The green wood was first heated in air from room temperature to $340^{\circ} \mathrm{C}$. The pressure in the reactor was then brought to $0.7 \mathrm{MPa}$ and heating was continued until the desired temperature had been reached. The reactor pressure was adjusted by releasing gas during heat treatment using a control valve on the reactor tube.

The temperature of heat treatment, from 450 to $550^{\circ} \mathrm{C}$, was also evaluated at $0.7 \mathrm{MPa}$ for 1 day in terms of its effect on anodic performance. After grinding the char into $45-\mu \mathrm{m}$ particles, all samples were heated at $800^{\circ} \mathrm{C}$ (heating rate: $5{ }^{\circ} \mathrm{C} \mathrm{min}^{-1}$ ) for $30 \mathrm{~min}$ in an argon atmosphere (Ar flow: $200 \mathrm{~mL} \mathrm{~min}^{-1}$ ) to remove any volatile components from the ground char. Hard carbon was prepared from the char samples by carbonizing at $1000^{\circ} \mathrm{C}$ (heating rate: $15^{\circ} \mathrm{C}$ $\mathrm{min}^{-1}$ ) for $1 \mathrm{~h}$ under vacuum (30 Pa).

\subsection{Characterization}

The relative weight loss from the green mangrove was determined by thermogravimetry (TG, EXSTAR6000; SII NanoTechnology). A dried sample of green mangrove tree powder was held in an alumina pan and heated to $1000^{\circ} \mathrm{C}$ at a heating rate of $5^{\circ} \mathrm{C} \mathrm{min}^{-1}$ under a flow of nitrogen gas $\left(100 \mathrm{~mL} \mathrm{~min}{ }^{-1}\right)$.

Carbon, hydrogen, and nitrogen content were determined using a CHN analyzer (MT-5; Yanagimoto CHN corder). Oxygen content $\left(\mathrm{O}_{\text {diff }}\right)$ was defined as the difference resulting from the subtraction of the sum of $\mathrm{C}, \mathrm{H}, \mathrm{N}$, and ash from $100 \%$.

The structural properties of the resulting mangrovederived hard carbon were characterized by X-ray diffraction (XRD) using a Rigaku X-ray diffractometer with a Cu Ka $(\lambda=0.15406 \mathrm{~nm})$ source. Adsorption/desorption isotherms of $\mathrm{N}_{2}$ and $\mathrm{CO}_{2}$ at $77 \mathrm{~K}$ and $298 \mathrm{~K}$, respectively, were determined with a Belsorp-Max-S from MicrotracBEL Corp. $\mathrm{CO}_{2}$ adsorption/desorption isotherms were obtained at low pressure $(<10 \mathrm{kPa})$ to determine the distribution of ultramicropore size based on a DFT model.

Electrochemical measurements were performed using CR2032 two-electrode coin cells. The electrodes were prepared by coating the mixed slurry, which consisted of $90 \mathrm{wt} \%$ active material, $5 \mathrm{wt} \%$ styrene butadiene rubber (SBR), and $5 \mathrm{wt} \%$ carboxymethyl cellulose (CMC) dissolved in distilled water, onto copper foil. Sodium metal foils were used as the counter and reference electrodes, and $1 \mathrm{M}$ $\mathrm{NaPF}_{6}$ dissolved in propylene carbonate (PC) (Tomiyama Pure Chemical Industry) was used as the electrolyte. The assembled coin cells were first charged from open circuit voltage to $0.003 \mathrm{~V}$ versus $\mathrm{Na} / \mathrm{Na}^{+}$at a current density of $30 \mathrm{~mA} \mathrm{~g}^{-1}$, followed by constant voltage charging at $0.003 \mathrm{~V}$ until the current density decreased to $3 \mathrm{~mA} \mathrm{~g}^{-1}$ (Toscat-3100; Toyo System).

\section{Results and discussion}

\subsection{Effects of preheating in the manufacture of mangrove-derived hard carbon}

Figure 1a shows a typical SEM micrograph of green mangrove wood. Several oriented structures are evident due to long growth time. These structures suggest that heat treatment would yield hard carbon with a high degree of carbonization.

To confirm the effects of preheating, green mangrove wood was subjected to two different heat treatment methods. Non-preheated mangrove char (NP-MC) was heated directly from room temperature to $800^{\circ} \mathrm{C}$ at $5{ }^{\circ} \mathrm{C} \mathrm{min}$. Preheated mangrove char (P-MC) was heated from room temperature to $500{ }^{\circ} \mathrm{C}$ at $0.7 \mathrm{MPa}$ for 1 day, then heated to $800^{\circ} \mathrm{C}$. Figure $1 \mathrm{~b}$ shows the mass yield of mangrove char. The NP-MC exhibited a much lower weight yield than the P-MC, which was $24.8 \%$. The preheating of green mangrove wood increased the mass yield of char. The physical characteristics of NP-MC and P-MC were investigated by XRD and Raman spectroscopy. The results are shown in Fig. 2a, b. The diffractogram of MC-NPT (mangrove-non preheat treatment) contained a very broad and weak peak near $26^{\circ}$ with several small impurity peaks. Despite several peaks corresponding to impurities, the preheated hard carbon (MC-T500h6) clearly showed a turbostratic carbon structure. Raman spectra yielded additional information on the structural properties of the hard carbon surface. In Fig. 2b, peaks corresponding to surface disorder and defects presented as a D-band at $1350 \mathrm{~cm}^{-1}$ and a G-band 

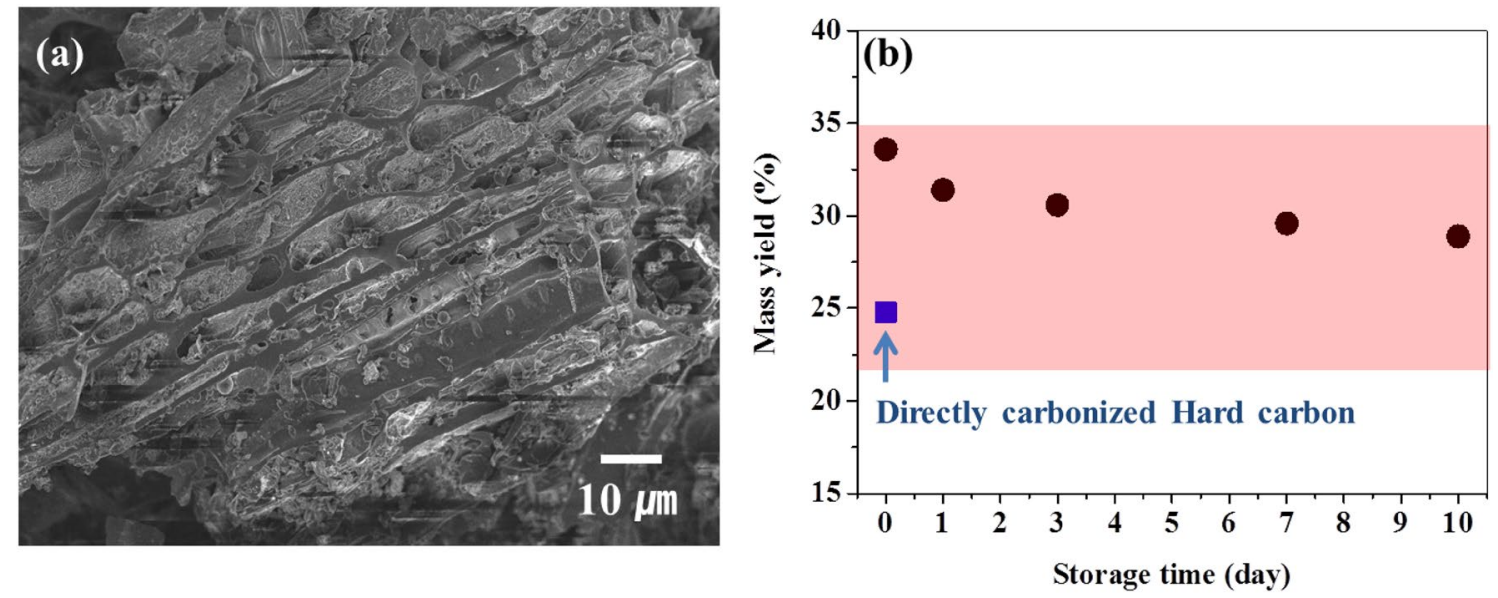

Fig. 1 a SEM micrographs of green mangrove wood and $\mathbf{b}$ product yield of mangrove char after heat treating at $800^{\circ} \mathrm{C}$
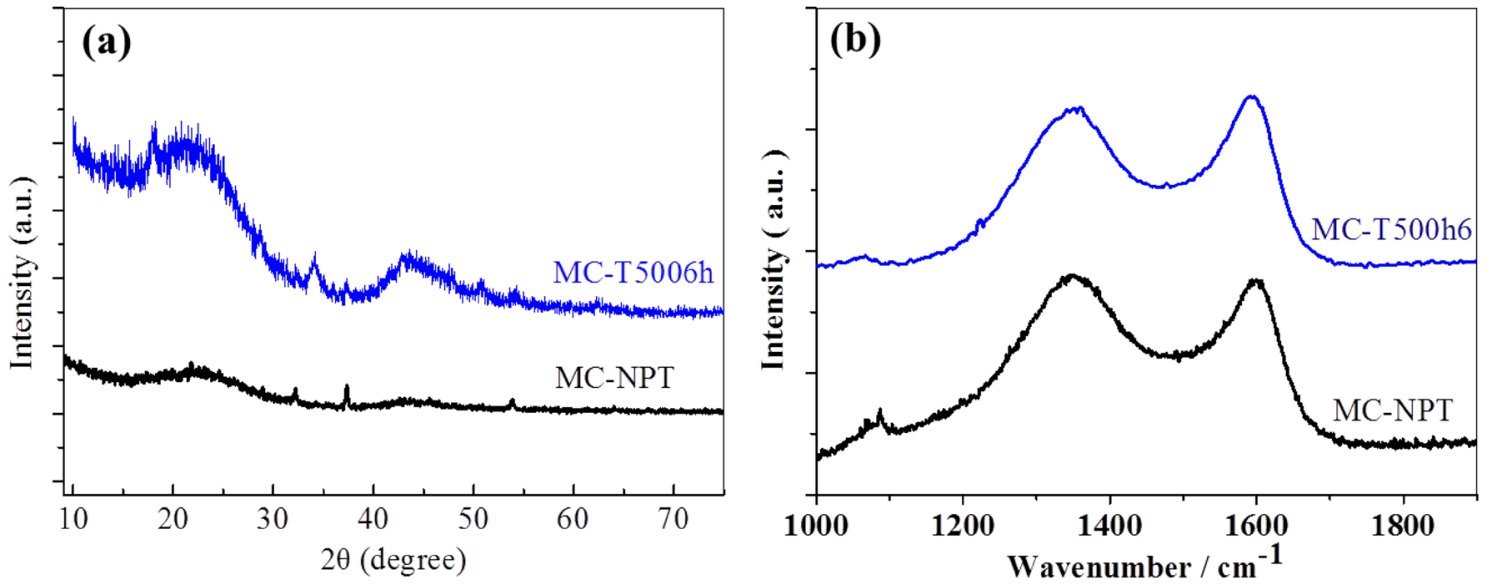

Fig. 2 a XRD diffractograms and $\mathbf{b}$ Raman spectra of directly carbonised hard carbon and hard carbon samples that had been preheated at $500^{\circ} \mathrm{C}$ for $6 \mathrm{~h}$

at $1590 \mathrm{~cm}^{-1}$, indicating a graphitic structure. The intensity ratio of the D-band and G-band $\left(\mathrm{I}_{d} / \mathrm{I}_{\mathrm{g}}\right)$ of NP-MC was 1.02 , much higher than that of MC-NPT (0.97). Thus, the degree of disorder in the hard carbon decreased with the addition of a preheating step.

Generally, heating at approximately $500{ }^{\circ} \mathrm{C}$ induces a coking reaction that converts organic material to insoluble carbonaceous material through the formation of polyaromatic compounds and their partial cross-linking with $\mathrm{sp}^{3}$-hybridized carbon with heat dissipation. In such competitive and complex reactions, low-temperature preheating can lead to a synergistic effect on $\mathrm{sp}^{2}$ bond formation. This process also eliminates unnecessary volatiles and thereby enhances the relative proportion of organic bonds, resulting in high carbon yields [11,12].

Figure 3 shows charge/discharge profiles of hard carbon samples obtained at a current density of $30 \mathrm{~mA} / \mathrm{g}$

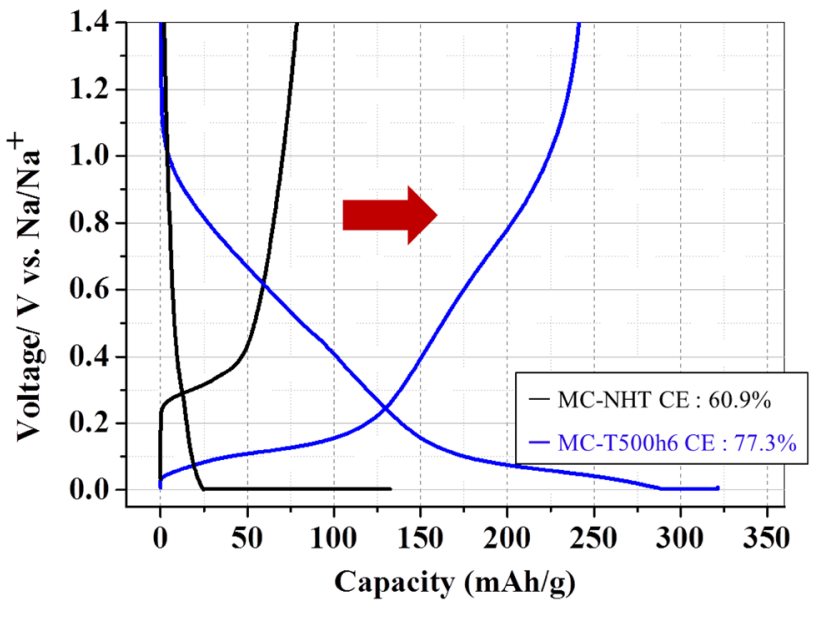

Fig. 3 First galvanostatic charge/discharge profiles of mangrovederived, directly carbonised hard carbon and hard carbon samples that had been preheated at $500^{\circ} \mathrm{C}$ for $6 \mathrm{~h}$

SN Applied Sciences 
between 0.003 and $1.5 \mathrm{~V}$ versus $\mathrm{Na} / \mathrm{Na}^{+}$. After preheating, the specific discharge capacity and the Coulombic efficiency were $250 \mathrm{~mA} / \mathrm{g}$ and $77.3 \%$, respectively. In particular, the specific discharge capacity of P-MC increased more than three-fold after preheating. This profile suggests that sodium ions were inserted directly into heat-treated hard carbon derived from mangrove char. Therefore, preheating significantly improves product yields and the electrochemical properties of hard carbon anodes.

\subsection{Effects of preheating conditions on electrochemical performance in SIBs}

The influence of heat-treatment temperature was evaluated to identify the optimum conditions for char production from green mangrove wood. Figure 4 shows the first-charge/discharge profiles of as-prepared hard carbon samples made from chars prepared at $450-550^{\circ} \mathrm{C}$ for $12 \mathrm{~h}$. Compared to those heated at $450^{\circ} \mathrm{C}$ and $550^{\circ} \mathrm{C}$, hard carbon from chars that had been preheated at $500^{\circ} \mathrm{C}$ exhibited a relatively high first-cycle Coulombic efficiency of $77.3 \%$ and a specific discharge capacity of $249 \mathrm{mAh} \mathrm{g}^{-1}$. Thus, the optimal preheating temperature was $500^{\circ} \mathrm{C}$. This temperature yielded the best trade-off between volatile loss and the formation of organic bonds. Both discharge capacity and the first-cycle Coulombic efficiency improved with longer preheating stages.

Figure 5 shows charge/discharge profiles at the first cycle of as-prepared hard carbons that were preheated at $500{ }^{\circ} \mathrm{C}$ and $0.7 \mathrm{MPa}$ for $1-10$ days. The hard carbon made from char that had been preheated for 7 days exhibited an $80.0 \%$ Coulombic efficiency and a specific discharge capacity of $284 \mathrm{mAh} \mathrm{g}^{-1}$. Both of these metrics decreased with longer heat treatments. This suggests that

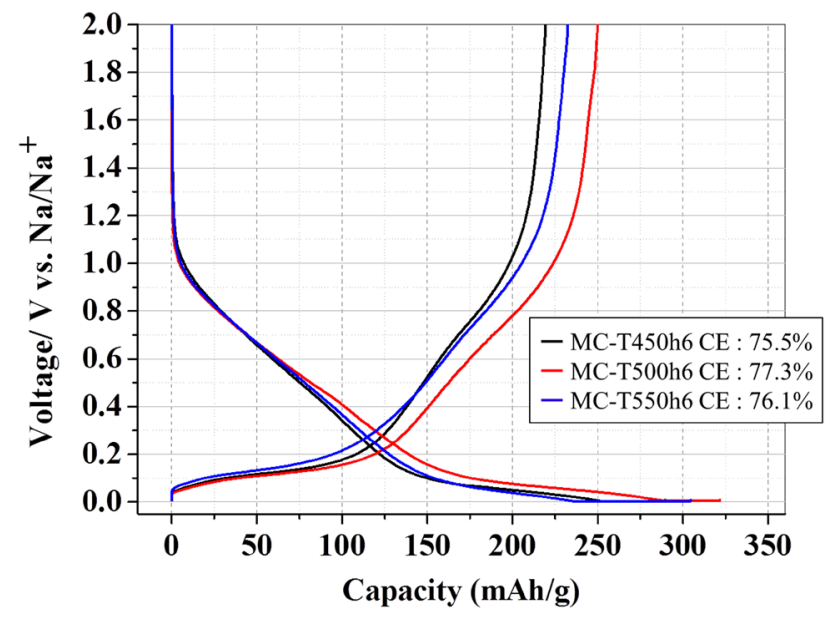

Fig. 4 The first galvanostatic charge/discharge profiles of mangrove-derived hard carbons processed with different preheating temperatures

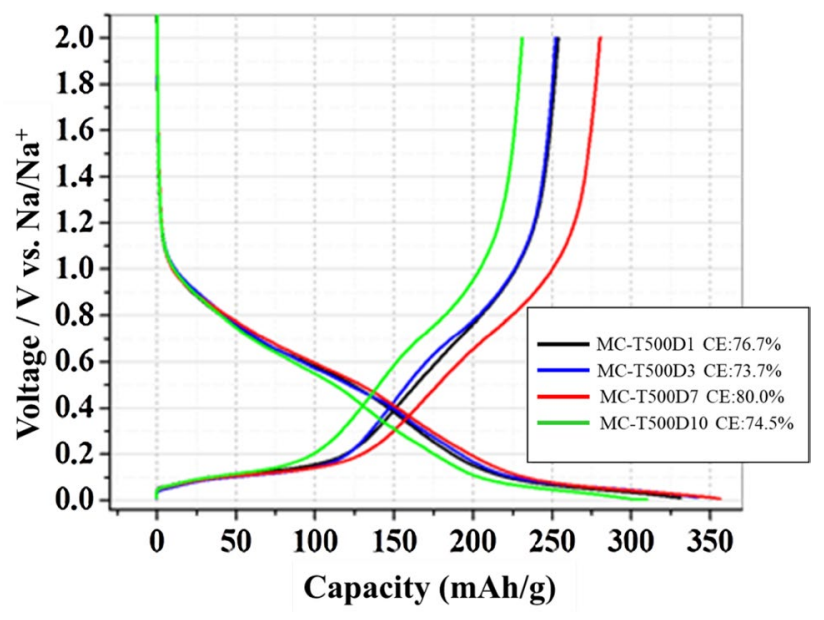

Fig. 5 First galvanostatic charge/discharge profiles of mangrovederived hard carbons processed with different preheating durations at $500^{\circ} \mathrm{C}$

nanoporous and turbostratically disordered graphene sheet structures can change during long-term preheating. In particular, the first-cycle Coulombic efficiency of MCT500D7 was significantly higher than those of the other samples. All samples exhibited similar charge processes, indicating similar amounts of electrolyte decomposition. Thus, preheating did not have a significant influence on the prevalence of side reactions during charging or discharging. Preheating did, however, affect the de-insertion of sodium ions from disordered graphene layers. Therefore, the best preheating conditions for preparing anodesuitable char from mangrove wood was $500^{\circ} \mathrm{C}$ for 7 days.

The rate performances of hard carbon samples derived from preheated mangrove chars are shown in Fig. 6 at discharge rates from 30 to $1500 \mathrm{~mA} \mathrm{~g}^{-1}$. The

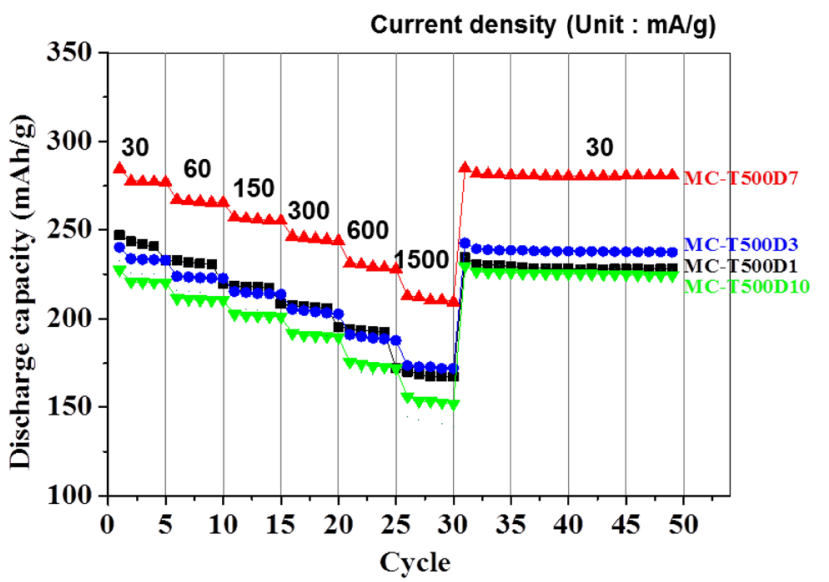

Fig. 6 Rate performance at incremental current densities from $30 \mathrm{~mA} \mathrm{~g}^{-1}$ to $1500 \mathrm{~mA} \mathrm{~g}^{-1}$ for mangrove-derived hard carbons with different preheating durations at $500^{\circ} \mathrm{C}$ 
Table 1 Discharge capacities of different current density and retention rate of mangrove-derived hard carbon with with different preheat treatment temperature

\begin{tabular}{llll}
\hline Sample name & \multicolumn{2}{l}{ Rate capability $(\mathrm{mAh} / \mathrm{g})$} \\
\cline { 2 - 4 } & $\begin{array}{l}30 \mathrm{~mA} / \mathrm{g} \text { after } \\
5 \mathrm{cycle}\end{array}$ & $\begin{array}{l}1500 \mathrm{~mA} / \mathrm{g} \\
\text { after } \\
5 \mathrm{cycle}\end{array}$ & $\begin{array}{l}\text { Retention } \\
\text { rate }(\%)\end{array}$ \\
\hline MC-T500D1 & 233 & 167 & 71.7 \\
MC-T500D3 & 233 & 172 & 73.8 \\
MC-T500D7 & 278 & 210 & 75.5 \\
MC-T500D10 & 220 & 152 & 69.1 \\
\hline
\end{tabular}

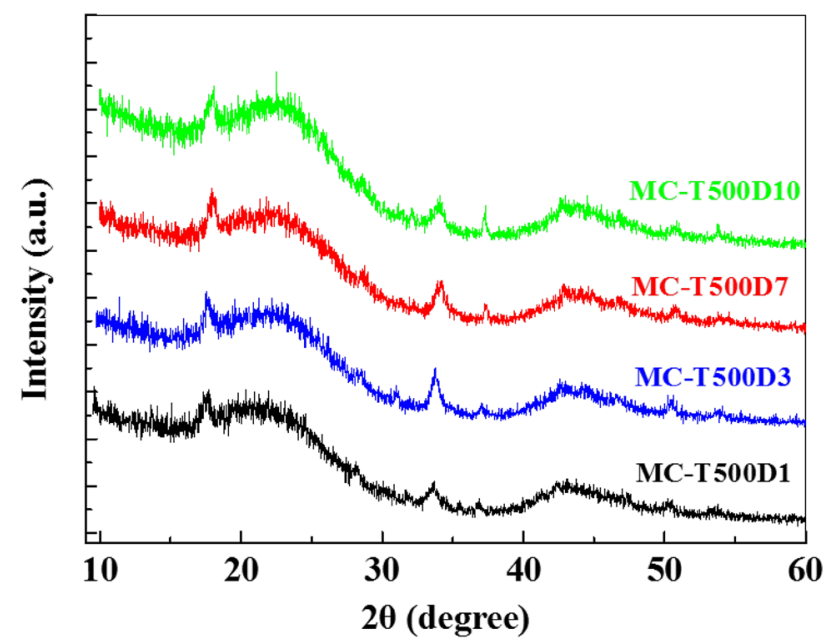

Fig. 7 XRD diffractograms of hard carbons prepared under a variety of fabrication conditions

discharge capacity at each rate and the retention rate $\left(1500 \mathrm{~mA} \mathrm{~g}^{-1} / 30 \mathrm{~mA} \mathrm{~g}^{-1}\right)$ of the discharge capacity were calculated and are shown in Table 1. In all cases, due to

(a)

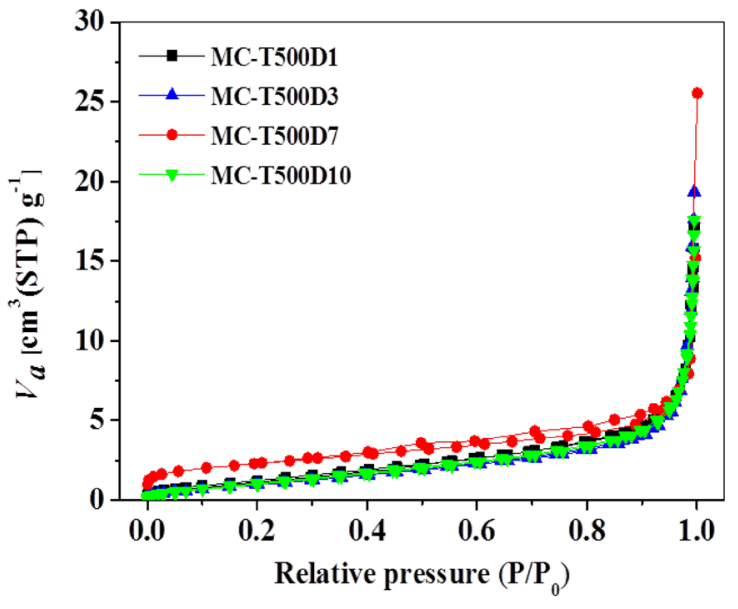

the irreversibility of sodium ionization, discharge capacity decreased rapidly after the first cycle and then stabilized. As-prepared hard carbon showed greater discharge capacities at higher current rates with longer preheating durations up to 7 days. The highest rate performance showed a capacity of $210 \mathrm{mAh} \mathrm{g}^{-1}$ at $1500 \mathrm{~mA} \mathrm{~g}^{-1}$ and a retention rate of $75.5 \%$. MC-T500D7, the hard carbon sample that had been preheated at $500{ }^{\circ} \mathrm{C}$ for 7 days, yielded a disordered carbon layer that might be well-suited to sodium ion insertion and de-insertion. The electrochemical performance of any given hard carbon sample depended largely on its structural properties. Therefore, the structural properties of hard carbons derived from mangrove wood that had been preheated for different durations were investigated by XRD and adsorption/desorption isotherm analyses.

Figure 7 shows XRD diffractograms of hard carbon samples prepared under a variety of fabrication conditions. All samples yielded a broad and weak diffraction peak at approximately $2 \theta=24^{\circ}$ and $43^{\circ}$, corresponding to the (002) and (100) planes, respectively, which are characteristic of low degrees of graphitization and turbostratically disordered structures. The interlayer distance between graphitic layers in our hard carbon samples was calculated to be $0.37-0.38 \mathrm{~nm}$. As carbonization temperature increased, the (002) peak shifted to higher diffraction angles, corresponding to a decrease in interlayer spacing. The peaks around $2 \theta=18^{\circ}$ and $29^{\circ}$ increased markedly at higher carbonization temperatures and longer heating durations, indicating the existence of $\mathrm{Ca}(\mathrm{OH})_{2}$.

Nitrogen adsorption/desorption isotherms at $77 \mathrm{~K}$ are shown in Fig. 8 for mangrove char-derived hard carbons made with various preheating durations. The specific surface areas of samples MC-T500D1 to D10 were 3.6, 5.2, 6.8,

(b)

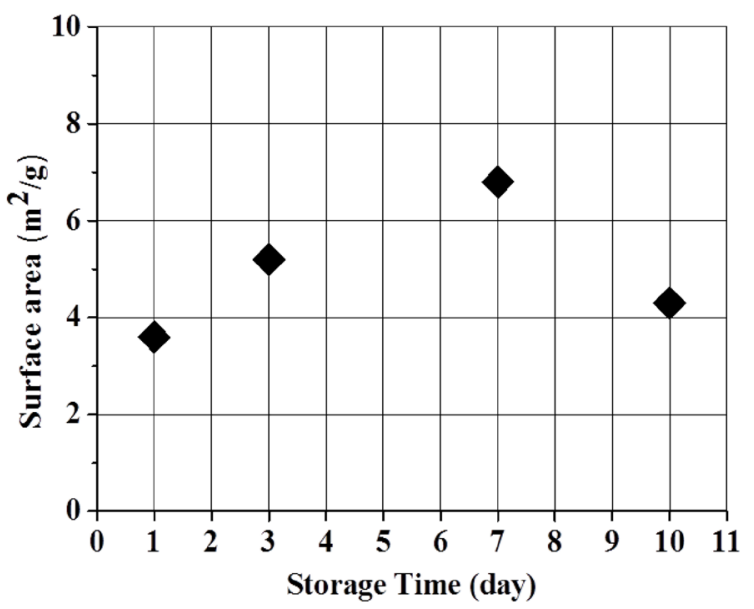

Fig. 8 a $\mathrm{N}_{2}$ adsorption/desorption isotherms at $77 \mathrm{~K}$ and $\mathbf{b}$ surface areas of mangrove-derived hard carbons made with different preheating durations at $500{ }^{\circ} \mathrm{C}$ 
(a)

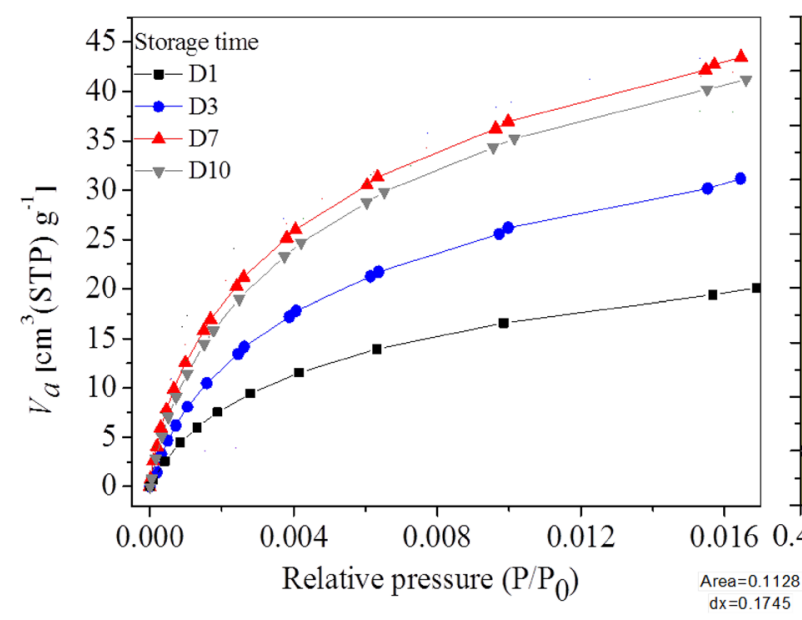

(b)

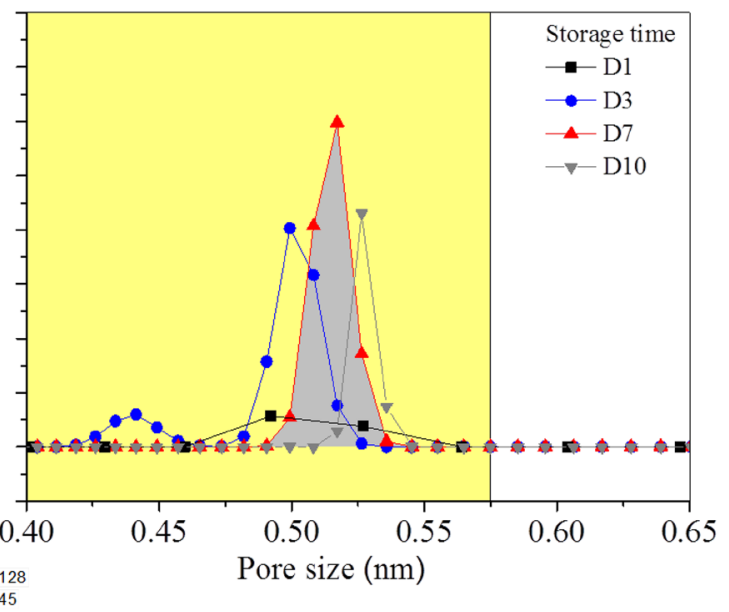

Fig. 9 a CO 2 adsorption/desorption isotherms at $298 \mathrm{~K}$ and $\mathbf{b}$ pore size distribution using DFT analyses of mangrove-derived hard carbons with different preheating durations at $500{ }^{\circ} \mathrm{C}$

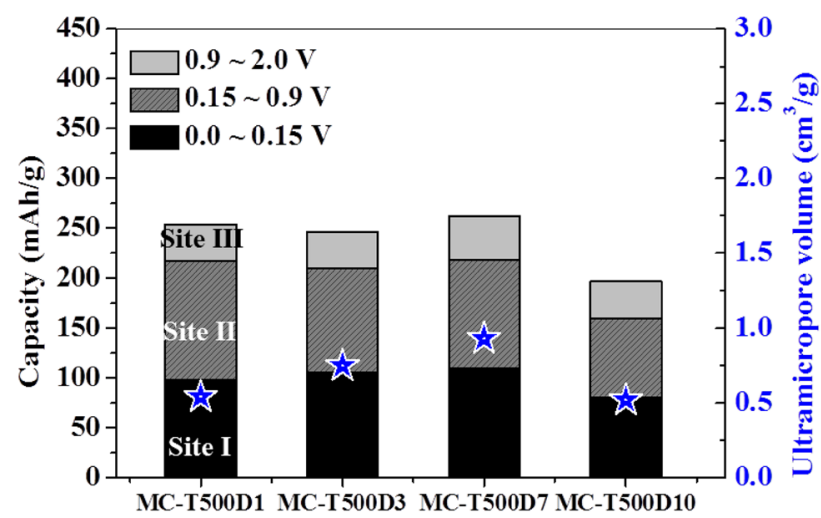

Fig. 10 A schematic diagram shows the relationship between discharge capacity and ultra-micropore volume

and $4.3 \mathrm{~m}^{2} \mathrm{~g}^{-1}$, respectively. Such low surface areas are not compatible with the observed charge capacities of these materials and the insertion of sodium ions. Therefore, nitrogen adsorption/desorption isotherms failed to detect the pores in these materials. Figure 9 shows the $\mathrm{CO}_{2}$ adsorption/desorption isotherms and the corresponding pore size distributions obtained using NLDFT (non localized density functional theory) methods on our prepared hard carbons. The pore diameter in mangrove char-derived hard carbons was distributed primarily between 0.45 and $0.55 \mathrm{~nm}$, which can be referred to as ultra-micropores. The average ultra-micropore diameter increased with the duration of preheating. In our previous study, we suggested that the existence of suitably sized ultra-micropores in the anode material improves the electrochemical performance of LIBs [11]. Optimal electrochemical properties were observed with sample MC-T500D7. It can therefore be presumed that ultra-micropores, formed in hard carbons that have been preheated at $500^{\circ} \mathrm{C}$ for 7 days, provide a good environment for the insertion and de-insertion of sodium.

The relationship between the discharge capacity in the first charge cycle and ultra-micropore volume is shown in Fig. 10. Individual discharge capacities for Sites I-III are given Table 2. Previous researchers have suggested that the discharge capacity of hard carbon can be divided into three regions. Region 1 (below $0.15 \mathrm{~V}$ ) is a discharge plateau that is believed to reflect the filling of pores (named Site I) by sodium metal (nanopore filling). Region 2 (below $0.9 \mathrm{~V}$ ) is due to the intercalation of $\mathrm{Na}$ between turbostratically disordered graphene sheets (Site II). Region 3 is a discharge plateau at around $1.3 \mathrm{~V}$, wherein $\mathrm{Na}$ is covalently bonded to edge sites on the graphene layer, especially in the vicinity of hydrogen atoms. These are considered storage sites (Site III) [13]. Significant discharge capacity corresponds to the low voltage region, and it has been suggested that this low-voltage plateau is related to the filling of pores with sodium ions. Figure 10 shows that the discharge capacity of Site I is directly correlated with ultra-micropore volume. We therefore believe that these ultra-micropores have a significant effect on the reversible sodium ion storage sites in hard carbon. 
Table 2 Discharge capacities divided into 3 sites of mangrovederived hard carbon with different pre-heat treatment temperature

\begin{tabular}{lllll}
\hline Sample name & \multicolumn{5}{l}{ Discharge capacity $(\mathrm{mAh} / \mathrm{g})$} \\
\cline { 2 - 5 } & $\begin{array}{l}\text { Total } \\
(0.0-\end{array}$ & $\begin{array}{l}\text { Site I }(0.0- \\
0.15 \mathrm{~V})\end{array}$ & $\begin{array}{l}\text { Site II } \\
(0.15- \\
0.9 \mathrm{~V})\end{array}$ & Site III (0.9 ) \\
& $1.5 \mathrm{~V})$ & & 113 & 37 \\
\hline MC-T5001D & 254 & 98 & 112 & 38 \\
MC-T5003D & 255 & 105 & 130 & 44 \\
MC-T5007D & 284 & 110 & 120 & 32 \\
MC-T50010D & 232 & 80 & &
\end{tabular}

\section{Conclusions}

A preheating process was developed to prepare hard carbon from mangrove wood for use as an anode material in $\mathrm{SIBs}$. The optimum preheating conditions for the preparation of mangrove char were 7 days at $500^{\circ} \mathrm{C}$ in a $0.7-\mathrm{MPa}$ atmosphere. Hard carbon that had been treated in this way exhibited a sustained rate capability and a discharge capacity and first-cycle Coulombic efficiency of $284 \mathrm{mAh}$ $\mathrm{g}^{-1}$ and $80.0 \%$, respectively. Pre-heating conditions were shown to control the pore structure in the resulting hard carbon. Ultra-micropores were shown to play a role in the formation of reversible ion storage sites for sodium ions.

Acknowledgment This work was partially supported by the Korea Institute of Chemical Technology (KRICT).

\section{Compliance with ethical standards}

Conflict of interest The author(s) declare that they have no competing interests.

\section{References}

1. Yabuuchi N, Kubota K, Dahbi M, Komaba S (2014) Research development on sodium-ion batteries. Chem Rev 114:11636-11682
2. Stevens DA, Dahn JR (2001) The mechanisms of lithium and sodium insertion in carbon materials. J Electrochem Soc 148:A803-A811

3. Fey GTK, Chen KL, Chang YC (2002) Effects of surface modification on the electrochemical performance of pyrolyzed sugar carbons as anode materials for lithium-ion batteries. Mater Chem Phys 76:1-6

4. Fey GTK, Kao YC (2002) Synthesis and characterization of pyrolyzed sugar carbons under nitrogen or argon atmospheres as anode materials for lithium-ion batteries. Mater Chem Phys 73:37-46

5. Peled E, Eshkenazi V, Rosenberg Y (1998) Study of lithium insertion in hard carbon made from cotton wool. J Power Sources 76:153-158

6. Zhang Y, Zhang F, Li GD, Chen JS (2007) Microporous carbon derived from pinecone hull as anode material for lithium secondary batteries. Mater Lett 61:5209-5212

7. Fey GTK, Lee DC, Lin YY, Kumar TP (2003) High-capacity disordered carbons derived from peanut shells as lithium-intercalating anode materials. Synth Met 139:71-80

8. Fey GTK, Chen CL (2001) High-capacity carbons for lithium-ion batteries prepared from rice husk. J Power Sources 97:47-51

9. Giri C, Ochieng E, Tieszen LL, Zhu Z, Singh A, Loveland T, Masek J, Duke N (2011) Status and distribution of mangrove forests of the world using earth observation satellite data. Glob Ecol Biogeogr 20:154-159

10. Liu T, Luo R, Qiao W, Yoon S-H, Mochida I (2010) Microstructure of carbon derived from mangrove charcoal and its application in Li-ion batteries. Electrochim Acta 55:1696-1700

11. Han Y-J, Chung D-B, Nakabayashi K, Chung J-D, Miyawaki J, Yoon S-H (2016) Effect of heat pre-treatment conditions on the electrochemical properties of mangrove wood-derived hard carbon as an effective anode material for lithium-ion batteries. Electrochim Acta 213:432-438

12. Moreau RA, Hicks KB, Powell MJ (1999) Effect of heat pretreatment on the yield and composition of oil extracted from corn fiber. J Agric Food Chem 47:2869-2871

13. Park CW, Yoon SH, Lee $\mathrm{SI}$, Oh SM (2000) $\mathrm{Li}^{+}$storage sites in nongraphitizable carbons prepared from methylnaphthalenederived isotropic pitches. Carbon 38:995-1001 